University of South Florida

DIGITAL COMMONS

Digital Commons @ University of

@ UNIVERSITY OF SOUTH FLORIDA

South Florida

Academic Resources Faculty and Staff

Publications

Tampa Library

December 2007

\title{
To Check In or Not To Check In? That is the question
}

Carol Ann Borchert

University of South Florida, borchert@usf.edu

Follow this and additional works at: https://digitalcommons.usf.edu/tlar_pub

Part of the American Studies Commons, and the Library and Information Science Commons

\section{Scholar Commons Citation}

Borchert, Carol Ann, "To Check In or Not To Check In? That is the question" (2007). Academic Resources Faculty and Staff Publications. 4.

https://digitalcommons.usf.edu/tlar_pub/4

This Article is brought to you for free and open access by the Tampa Library at Digital Commons @ University of South Florida. It has been accepted for inclusion in Academic Resources Faculty and Staff Publications by an authorized administrator of Digital Commons @ University of South Florida. For more information, please contact digitalcommons@usf.edu. 
To Check In or Not To Check In? That is the question

Carol Ann Borchert, University of South Florida

\section{Abstract:}

The University of South Florida Tampa Library discontinued checking in print journals and periodicals for a trial period of one year from July 2005 to June 2006. This article discusses the reasons behind such a decision, how it worked out, and what the ramifications have been. Though it proved inconvenient for public and technical services alike, few specific problems were reported via email, online forms or in person. The library derived several benefits from this project, particularly in terms of the timing, since it happened just as the library moved to a new integrated library system, from NOTIS to Aleph.

Introduction

There has been much controversy in the past few years surrounding the topic of whether to continue check-in for print periodical titles. Many of the articles published on the topic note that until 2002, there was little discussion of whether libraries should check in print journals, but rather a focus on the best way to do so. In Rick Anderson's article, "A Sacred Cow Bites the Dust," he states: "[S]loppiness in the management of our little-used print journals is a fair price to pay for a significant increase in our effectiveness at providing the materials our patrons do use, in the format in which they clearly prefer to use them."1 University of Nevada-Reno has successfully discontinued check-in for the purpose of reallocating staff in order to pay closer attention to the online titles. University of Montana, on the other hand, assigned a group to consider the pros and cons of discontinuing check-in and decided to continue with the practice of checking in print journals mainly because, for their institution, it would not save them much staff 
time and effort. ${ }^{2}$ Carr compares the three main objectives for print check-in and examines how these translate in an electronic environment. The objectives as he states them are as follows:

1. Check-in enables libraries to inform users of serial content available for access. ...

2. Check-in enables libraries to maintain bibliographic control of serial entities. ...

3. Check-in enables libraries to act as stewards of serial investments. ${ }^{3}$ Carr then examines the difficulties in achieving these objectives in an electronic environment, where information is available at the article-level, not just at the issue level. In the print environment, libraries could run a claims report to see what had been paid for and not received. Carr observes that finding missing issues for electronic serials, on the other hand, involves "a network of resources, including publisher-supplied information, subscription agents, an ERM system, and of course, users' complaints." ${ }^{4}$ In an environment where libraries dedicate more and more of their budgets to online resources over print, and users indicate a heavy preference for that format, how useful is the time dedicated to checking in the print? This lack of traditional check-in for online titles has in part fueled the discussion of why libraries continue to manage the print so meticulously and whether it is worth the effort.

The University of Nevada-Reno (UNR) successfully discontinued journal checkin. In Anderson's article, "Implementing the Unthinkable," he notes that what the patrons want to know is whether the issues they seek are available or not. He also lists several reasons for this process in a print environment.

Traditionally, check-in has:

- recorded whether an issue has arrived; 
- provided a means to monitor changes in publication frequency and pattern;

- assisted in the detection of title changes, splits and mergers;

- driven routine claiming of missing issues; and

- served as a management mechanism for binding processes. ${ }^{5}$

He then explained how UNR is handling each of these functions now, but without checking in journals. Perhaps the biggest concern would be whether the library had the item. However, a notation in the online catalog indicating the library had the item in hand weeks ago is not helpful information for the patron today. The patron wants to know if we have the issue on the shelf now. ${ }^{6}$ UNR implemented a document delivery service with an average 24-hour turnaround time for patrons if the issue they sought was not immediately available on the shelf. Instead of asking patrons to return after seeking an issue that was missing from the shelf, the library obtained a copy immediately following the first failed search for the item and delivered it into the patron's hands. Anderson describes this change in public service philosophy from a patron viewpoint: With check-in, the tacit message to patrons had been 'You're looking for an article in the June issue of the Atlantic? Yes, that issue has been checked in. Go look on the shelves, and if it isn't there, try again later." The message now is "You're looking for an article in the June issue of the Atlantic? It should be in the Current Periodicals stacks. Check there, and if it isn't available at the moment, the University will get a copy of the article for you in about 24 hours at no charge. Would you like it delivered to your campus address in print form (again, at no charge), or would you like to be notified when you can retrieve it on the Web?" If the library implements a document delivery policy stating that if an issue is unavailable, the library will order a copy without delay, this is a great improvement over "try again 
later." Even with journal check-in, no one knows if the item will be available when and where the patron needs it.

\section{Background}

The University of South Florida (USF) Library System has six libraries. Three are located in Tampa: USF Tampa Library, Shimberg Health Sciences Library, and the Florida Mental Health Institute (FMHI) de la Parte Library. There are also libraries on the USF St. Petersburg, Sarasota, and Lakeland campuses. The Health Sciences Library and the St. Petersburg and Sarasota libraries receive and process their own print journals. The Technical Services area located in the USF Tampa Library processes titles for Tampa, Lakeland, and FMHI.

The University of South Florida has over 7,000 electronic journal subscriptions, and just over 3,100 print titles. We have access to 22,000 unduplicated titles online between our subscriptions and our aggregator databases. The USF Tampa Library claimed an average of $4 \%$ of its print titles over the course of a year. The USF Libraries E-Journal Management policy outlines criteria for cancelling print and moving to online. ${ }^{8}$ In addition to providing access for all USF students, no matter their geographic location, the title must be IP-authenticated, have some guarantee of perpetual access for our subscription, and the online copy must match or exceed the print copy. Under the guidelines of this policy, USF has been aggressively converting print titles to online whenever possible.

As a point of comparison, UNR has approximately the same number of print titles as the USF Tampa Library. At the time of Anderson's 2003 article, UNR had 2,700 print journals, whereas USF Tampa Library was receiving 3,129 print journal titles in 2005. At UNR, the current periodicals are located fairly close to the Reference area, and at the USF Tampa Library, bound and current periodicals are located on a separate floor 
(which also has a staffed service desk). Given that the University of South Florida Tampa Library's online journals constitutes the bulk of our journal collections, usage, and journal cost, it made sense to at least try the discontinuation of check-in.

In 2003, we had a new Director for Technology and Technical Services, who consistently asked the question: What can we stop doing? What are we doing now just because we've always done it? In fall 2003, he organized a group of people to examine all workflows for cataloging, acquisitions, and binding for our library. Their assignment was as follows: 1) to determine if staffing levels for that area were appropriate; 2) in anticipation of implementing a new library management system, to provide a benchmark of where our workflows stood so that we could visually see the general process, even though our procedures would be changing; 3 ) to evaluate all workflows and determine if streamlining could be done in the various areas of Technical Services. The Technical Services Plan for Optimization and Productivity group completed their report in June $2004 .^{9}$

That same summer, the Collection Development librarians conducted a usage study of the print newspaper collection, which resulted in the cancellation of several newspaper subscriptions. Most of these were by that time available and being used online. The library discontinued checking in daily newspapers, which has not caused any complaints. Again, many of these are available through aggregator services online, and the patrons using the print tend to go to the Periodicals service desk to request a specific newspaper issue rather than consulting the record in the catalog.

In July 2005, we moved from our NOTIS system to Ex Libris' Aleph system. This involved a great deal of staff training, especially since our state university system was still using a telnet system on the staff side, and Aleph is a Windows-based system. As a result of this move, the library lost data from our OPR (order-pay-receipt) records in NOTIS, including the current issue holdings, as there was no comparable place in Aleph 
to map that data. This left us with no listing of issues located in the Current Periodicals collection as of USF's Aleph switch-to-production date in June 2005. Technical Services staff members knew prior to moving to the new system that we would be losing this data, and that we would need to recover that information. Data in the OPR included the current issues received that year, plus many of the incomplete volumes from 2003 from the Faxon/divine bankruptcy.

Unlike NOTIS, Aleph uses MARC Holdings format, which was an entirely new skill for our Serials Acquisitions staff to acquire, in addition to becoming familiar with a new library management system. What better time to determine if discontinuing the check-in process would save staff time? Either we took advantage of the fact that we were losing data anyway, or we struggled to set up predictive check-in patterns using MARC Holdings format while handling a myriad of other duties and learning a completely new and different library management system. We chose the first of these two options.

\section{How We Stopped Checking In}

Preparing for the discontinuation of check-in involved multiple meetings of the Serials Acquisitions group. This group also met throughout the project to discuss workflow issues, particularly binding workflows, and how to best address them. Additionally, the Coordinator for Serials met with staff in Reference and Access Services, including Interlibrary Loan. The Coordinator for Serials and the Director of Technology and Technical Services (now Collection Analysis and Technical Services) met with the Reference and Instruction Services unit in May 2005 to notify them of our intent to discontinue check-in and to provide them the opportunity to ask questions about the process. We created an online form for librarians to request check-in for specific titles and sent information about this new form with the URL in periodic library-wide emails. The librarians did not use the form over the course of the year, but a few 
requests were sent directly to the Coordinator for Serials, particularly at the end of the evaluation period.

In July 2005, we met with Interlibrary Loan staff members to hear their concerns, and to determine a way for them to respond quickly to patron requests for articles. If an interlibrary loan request was for an issue that the library should have, ILL staff searched for it for 24 hours, then filled out a periodical search request form online. At that point, the Senior Library Technical Assistant (LTA) in Periodicals searched for the issue following the periodicals search procedure. Because we already had a book search request form online, it made sense to have this new periodicals search form online for general patron as well as staff use. Over the course of the year that we discontinued check-in, we had only six search requests for current issues that we should have received. The majority of search requests were for bound volumes. If a patron was already in the Periodicals area, the Senior LTA in Periodicals searched for the issue, then marked it in the holdings record as missing so that the patron could request that article immediately through interlibrary loan. Reviewing the ILL statistics for that year from the ILLiad system, there were twenty requests for current issues from ten titles for which the USF Tampa Library had current subscriptions. Most of these currently show as available either in print or online. One title was discontinued in 2005.

We also met with the shelving supervisors in Access Services. Ideally, the student assistant shelvers would have alerted us when issues were missing, but the supervisors in that area had concerns. In addition to the time and training involved for the student assistants, they were not confident that their shelvers would notice when there was a significant gap in a volume as they shelved current issues. We decided instead that staff in Serials Acquisitions would periodically check sections of the current issues collection to determine what was not being received. 
The Director of Technology and Technical Services met with the directors of the other USF Libraries to provide information about this project. He gave them a two-page information sheet outlining the reasons for discontinuing check-in and how problems would be handled. It also outlined measures of success for the project:

- realizing a time savings for Serials unit staff such that they spend less than 25 percent of their assignment on matters pertaining to print serial tracking, claiming, and troubleshooting;

- experiencing a minimal number of service problems as determined by tracking incoming requests for assistance via the RightNow application; and

- realizing cost savings absent negative fiscal implications. ${ }^{10}$

Because the other USF libraries often referred patrons to the USF Tampa Library for print periodicals, they needed to know that our current issues would not be listed in the system. To confirm that an issue was on the shelf, they needed to call the Periodicals desk in the USF Tampa Library before sending a patron from a nearby city to use a title in that building.

Starting in July 2005, at the beginning of the test period, updates and information were periodically sent to the staff of the USF Libraries to notify them of reasons for discontinuing check-in, progress, and tools available to them for reporting problems. We continued to check in titles from the Lakeland and FMHI libraries, which have small journal collections, and for the Special Collections area. Serials and standing orders (defined in our library as anything received once a year or less) are located in the circulating collection and are bound upon receipt. Discontinuing check-in was originally started as a 6-month trial, which later extended to a full fiscal year. A final report is posted on the libraries' Web site at http://www.lib.usf.edu/public/_files/serialspilot200506.pdf. 


\section{Preparation and Workflows}

Our Periodicals collection is arranged by call number, not by title. Early in our discussions with Public Services, the librarians clearly stated that it was not acceptable to reorganize the current journals by title in order to facilitate shelving without having to search for the call number for each title on receipt. They did, however, assist us in compiling a spreadsheet of titles with call numbers to use as a quick reference so that staff members could easily write a call number and attach it to the piece in hand. Staff in Serials Acquisitions used macros to add notes to the records, as follows:

- For current journals: "FOR CURRENT ISSUES OF THIS TITLE, PLEASE CHECK THE CURRENT PERIODICALS SHELVES"

- For journals already converted to online-only: "Library has discontinued its subscription to the print."

- For new titles: "Library's subscription begins with: [v.] [year]"

As current issues were bound, they were added to the holdings record for the bound volumes. Titles that were later replaced with microform were marked with an orange dot on the current issues box so that they would not be pulled for binding. Theoretically, we would only have one year of issues not listed in the holdings record. However, incomplete volumes that had not yet been sent to the bindery were also not listed in the holdings record.

We had hoped to have a student assistant process the current periodicals issues in order to move this work away from the Senior LTAs, but did not have enough assigned hours to complete this task. Processing a title included looking it up on the spreadsheet, noting any special processing notes or locations listed therein, labeling the title with a handwritten label, stamping the title, and sending it upstairs. Any problems or questions were to be given to the Senior LTAs, including any titles with special supplemental materials, such as a CD-ROM. During this time, we also lost a staff 
position in the Serials Acquisitions area, further stressing the remaining staff as they tried to absorb these duties and learn a new system.

We opted to continue binding periodical titles, which created many problems. We struggled throughout the project to streamline a workflow so that when an item was ready to bind, the binding unit staff would know to pull the volume for binding. Because our Collection Development unit's policy is to bind a full volume, we could not bind a volume until all issues were found or purchased. Since we were not checking in, we could not really claim issues as the problem arose, and claiming at the point of binding is often too late.

Reference librarians have observed that patrons in the USF Tampa Library have a real hesitation to use the print. It makes sense that patrons who are at home or distance learners located in another city would find it inconvenient to come to the library to use the print. However, patrons located at the computers on the first floor of the building prefer to search for a different article online rather than walk up to the second floor to use the print. Not checking in titles apparently compounded this behavior, as there was no "guarantee" that the issue would be on the shelf. Despite the note in the holdings records in all caps to check the Current Periodicals shelves for current issues, there existed a mentality that if it was not listed in our holdings records, our library did not have it. We found this to be especially problematic for the periodicals located in Reference. Because the Reference collection titles did not have a set binding schedule due to their historically high usage, some titles had not been bound for several years. Unbound issues were no longer displaying in the OPAC, making it look in the record as if the library had not received it at all during that time. Our move to a new library management system highlighted a number of such problem areas that needed attention.

We had very few complaints over the course of a year from the Public Services staff, although we created an online form for librarians to request check-in for specific 
titles if they knew the print was used frequently and they needed the holdings data. Only three titles were requested, and none were through that form. As we neared the end of the trial period, and it became apparent that we might continue this indefinitely, some of the Public Services librarians began requesting check-in for an unspecified core list of titles for each academic subject area. There was also an increase in the number of specific titles being requested for check-in at the end of the trial period.

\section{$\underline{\text { Benefits }}$}

This project allowed the Serials Acquisitions staff time to adjust to a new system before having to set up predictive check-in patterns for 3,000-plus titles. Because we had to create a spreadsheet of our current titles, we found many file boxes upstairs for titles that had already been converted to online. The staff cleared one side of a row of shelving in the Current Periodicals area during this process, binding final volumes and sending single issues to back-issue services.

Reference and Information Services librarians are also now aware of the need to set up a consistent binding schedule for titles in the Reference collections. For titles that are not bound, staff members in Technical Services record the issue in the holdings record by hand versus using the predictive check-in function in Aleph. (Aleph lists current issues separately, which can become cumbersome if the title is never collated into a bound volume.) The Senior LTAs in Serials Acquisitions are currently updating those records, noting which titles are to be bound, and which titles should be added to the permanent section of the holdings record immediately rather than checked in as a single issue.

\section{How the Project Ended}


After doing time studies, we discovered that staff members were spending almost as much time not checking in the journals as they would checking them in using the Aleph predictive check-in function. (In Aleph, staff members can set up predictive receipt patterns using MARC Holdings format, which creates system-generated item records. When an issue arrives, a single click on that item record checks in that issue.) Staff timed the number of titles they processed for Tampa in a 15-minute period using the "non-check-in" process, versus how many titles they processed using the Aleph predictive check-in function. (See table 1)

Because Aleph uses a predictive check-in function, the process is much more efficient than it had been previously in NOTIS. Once the predictive pattern is set up in Aleph, staff search for a title and check in an issue with a single click. In NOTIS, staff had to look up a title and type in the issue information by hand. Given that two of our three staff members were able to check titles in as fast as not checking them in, we decided to reinstate check-in for current periodical titles. This has been phased in over time. As a new issue was received, and the binding pattern indicated the issue in hand should start a new volume, staff members set up the predictive pattern for that title and began checking in issues. Reinstatement of check-in was announced at a meeting of the Cataloging Policy Committee in July 2006, much to the jubilation of the Public Services representatives. Many of the Technical Services staff members seemed relieved to reinstate this process as well.

\section{What We Learned}

In order to successfully stop periodicals check-in, public services staff must fully support the idea, not just in concept, but in a cooperative way. Although they did not like not being able to read from the record which issues had been received, several of the Public Services librarians supported the idea that we needed to focus on the electronic 
titles and to shift titles from print to online. However, staff support from the people shelving the materials, who could communicate problems with non-receipt immediately, would have been very helpful.

Also, we never found a good way to continue binding while not checking in titles. This inability to find a smooth binding workflow was the main problem from the Technical Services viewpoint, and attempting to find or purchase missing issues cost valuable staff time. By contrast, University of Nevada-Reno discontinued the binding of their periodicals, instead grouping volumes together in boxes. Trying to have Technical Services staff set aside time to browse the collection for problem areas was a good idea in theory and would have helped determine when issues were ready for binding. However, for time-strapped staff members, going upstairs to look at the collection fell to the bottom priority. Relying on shelvers to do this would have been a great help, had this been possible.

The decision to keep the current issues collection in Library of Congress classification order instead of reshelving by title meant that we had to set up an alternate process to do a quick call number lookup. It is understandable that Public Services did not want to reorganize this collection for a test project, but it complicated workflows significantly. Though check-in on our old system required keying in the issue information by hand, doing so on the new system was much simpler. Therefore, the check-in and non-check-in workflows were quite similar, with check-in providing valuable information to facilitate the binding process.

We did not return to checking in daily newspapers, as that has not generated any complaints. Patrons using the paper copy of a newspaper seem to be comfortable going to the desk to request an issue instead of trying to interpret the holdings screens for a title received on a daily basis. 
The USF Tampa Library was fortunate to have had the opportunity to test this on a trial basis as we migrated to a new library management system. However, for our institution, this was not a success and seemed to create more problems library-wide than it solved. Given the many workflow complications we faced, it is apparent that journal check-in processes are significantly impacted by collection management policies. Complicating factors in the discontinuation of check-in included the arrangement of the collection, the continuation of binding, and the decision to bind only complete volumes. The information provided to the staff through the check-in process turned out to be even more important at our institution in determining the success of this project than the information displaying to the public. 


\section{Notes}

1. Anderson, Rick, "A Sacred Cow Bites the Dust," Library Journal 127, no.8 (May 1, 2002): 56 .

2. Millet, Michelle S. and Susan Mueller, "Shifting Priorities: Print and Electronic Serials at the University of Montana, "The Acquisitions Librarian 35/36 (2006): 145.

3. Carr, Patrick.L. "The Claim: Staking Out New Practices for Achieving the Objectives of Check-In," Serials Librarian 51, no.1 (2006): 75.

4. Ibid., 79 .

5. Anderson, Rick and Steven D. Zink, "Implementing the Unthinkable: The Demise of Periodical Check-In at the University of Nevada," Library Collections, Acquisitions, \& Technical Services 27 (2003): 64.

6. Ibid., 64 .

7. Ibid., 68-69.

8. For more information, please see Policy 12-401: E-Journal Management, available online at http://www.lib.usf.edu/public/ files/12401.pdf.

9. For further information, please see the Report of the Technical Services Plan for Optimization and Productivity, 2004, available at http://www.lib.usf.edu/public/ files/POP.pdf.

10. Borchert, Carol Ann and Chavez, Todd. Reallocating Serials Acquisitions Staff 2005-2006, University of South Florida Libraries, http://www.lib.usf.edu/public/_files/serialspilot200506.pdf. 
Table 1. Number of items processed in a 15-minute timeframe when not checking in versus traditional journal check-in on Aleph.

\begin{tabular}{|l|l|l|}
\hline & No check-in $^{\mathrm{a}}$ & Check-in $^{\mathrm{b}}$ \\
\hline Staff member 1 & 16 & 12.5 \\
\hline Staff member 2 & 9 & 9.5 \\
\hline Staff member 3 & 7 & 7 \\
\hline Average & $\mathbf{1 0 . 7}$ & $\mathbf{9 . 7}$ \\
\hline Mean & $\mathbf{9}$ & $\mathbf{9 . 5}$ \\
\hline
\end{tabular}

${ }^{a}$ Not checking in included the following tasks: Look up the title in an Excel spreadsheet, write the call number on a label, attach it to the issue, and send the issue upstairs. If it is the beginning of a volume, send a note to binding.

${ }^{b}$ Checking in included the following tasks: Look up the title in Aleph, click to "arrive" the item in the system, write the call number on a label, attach it to the issue, and send the issue upstairs. Claim as needed, and send a printout of the holdings record to binding as needed. 